http://jmscr.igmpublication.org/home/ ISSN (e)-2347-176x ISSN (p) 2455-0450 crossref DOI: https://dx.doi.org/10.18535/jmscr/v7i9.47

\author{
Journal Of Medical Science And Clinical Research

\title{
Role of Transvaginal Sonography and Hysteroscopy in Evaluation of Intrauterine Pathology in Abnormal Uterine Bleeding - A Comparative Study
}

\author{
Authors \\ Dr Arindam Mallik ${ }^{1}$, Dr Jayanta Ray ${ }^{2}$, Dr Mamata Pradhan ${ }^{3}$ \\ ${ }^{1}$ Senior Resident, ${ }^{2}$ Associate Professor, ${ }^{3}$ Professor \\ Dept of Obstetrics and Gynaecology, AGMC and GBP Hospital \\ *Corresponding Author \\ Dr Arindam Mallik
}

\begin{abstract}
Introduction: Present study comprised of TVS, diagnostic hysteroscopy for diagnosis and histopathology for confirmation of intrauterine pathology. The aim of the study is to narrow down the arrays of investigation, to develop a guideline for quick assessment and hence early management of patients complaining of $A U B$ in a cost effective manner which is essential in this low resource set up women are particularly vulnerable.

Material and Methods: It is a Prospective comparative study for a period of 1.5 years (January 17 to June 18).Women in reproductive and perimenopausal age complaining of AUB due to suspected intrauterine pathology (either intracavity lesions or pathology in the endometrium) were included in the study for further evaluation by TVS and hysteroscopy and directed biopsy wherever indicated.

Results: 75 cases were evaluated and most of the cases were multiparous in the age group of 30 -39 years and mean age of intrauterine pathology was 35.5 years. The maximum subject was complaining abnormal uterine bleeding for last $1-6$ months and $58 \%$ had heavy menstrual bleeding.TVS diagnosed endometrial polyp (32\%), endometrial hyperplasia (9\%) and submucosal fibroid (14.7\%) in maximum patients. Patients diagnosed with hysteroscopy had mainly endometrial polyp (32\%), endometrial hyperplasia (24\%) and submucosal fibroid (16\%).In endometrial hyperplasia, hysteroscopy was more sensitive than TVS, but, probability of the patients for truly have the disease is low in both TVS and hysteroscopy as diagnosed by HP examination. Hysteroscopy diagnosed endometrial polyp much better than TVS with high sensitivity, specificity and predictive values. Submucosal fibroid also diagnosed better by hysteroscopy with good predictive values. Both TVS and hysteroscopy were good diagnostic tools for carcinoma endometrium.

Conclusions: TVS should be continued as 1st line diagnostic tool in patients with AUB. Hysteroscopy is a better diagnostic method for intrauterine pathology in AUB. With combination of both TVS and hysteroscopy, the evaluation for AUB will be more accurate and will guide for appropriate management.
\end{abstract}

\section{Introduction}

Standardized terminology is essential in the discussion of abnormal uterine bleeding (AUB) to improve research works and management. AUB is the comprehensive term used to describe any departure from normal menstruation or from a normal menstrual cycle pattern. The key characteristics are regularity, frequency, heaviness 
and duration of flow, but each of these may exhibit considerable variability. ${ }^{1}$ Classic descriptions of AUB are based on the cyclicity and the quantity of menstrual flow. Because most cases are associated with anovulatory menstrual cycles, adolescents and premenopausal women are particularly vulnerable. About $20 \%$ of affected individuals are in the adolescent age group, and $50 \%$ of affected individuals are aged $40-50$ years. $^{2}$

The clinical approach to AUB requires prompt and efficient evaluation to exclude or diagnose the various causes. Transvaginal ultrasonography has been explored as a $1^{\text {st }}$ line diagnostic tool to identify the intrauterine lesions like submucous fibroid, polyp and septum etc. Hysteroscopy provides a simple \& easy method for visualization of the cervical canal, uterine cavity and tubal Ostia. It is also used for treating different kinds of intrauterine pathologies. Diagnostic hysteroscopy can be done in an office setting or in operation theatre. Advantages of hysteroscopy are that it helps in direct visualisation of intrauterine lesions which can be treated simultaneously with operative hysteroscope. Endometrial biopsy is an essential investigation performed in AUB to study the endometrium and so it is indispensable to exclude endometrial hyperplasia or cancer. ${ }^{3,4}$

Present study comprised of TVS, diagnostic hysteroscopy for diagnosis and histopathology for confirmation of intrauterine pathology. The aim of the study is to narrow down the arrays of investigation, to develop a guideline for quick assessment and hence early management of patients complaining of AUB in a cost effective manner which is essential in this low resource set up women are particularly vulnerable.

\section{Materials and Methods}

It is a Prospective comparative study conducted in the department of obstetrics and gynaecology, AGMC and GBP hospital, Agartala, Tripura for a period of 1.5 years (January 17 to June 18). The study subjects were the attending patients in gynaecology outpatient department of AGMC and
GBP hospital with complaint of AUB having suspected intrauterine pathology. The sample size for this study was approximately 75 by doing convenience sampling. The study conducted after due approval from the committee. Women in reproductive and perimenopausal age complaining of AUB due to suspected intrauterine pathology (either intracavity lesions or pathology in the endometrium) were included in the study for further evaluation by TVS and hysteroscopy and directed biopsy wherever indicated. Unmarried girl, women with Pregnancy / Intrauterine infections/ Cervical cancer / Active uterine bleeding (hysteroscopic visualization will be poor) / Postmenopausal women excluded.

TVS was done by ultrasonographic machine (model SONOACEX8, manufacturer by MEDISON, PROBE - 6 to $7.5 \mathrm{MHz}$ transducer) in radiology department. The subject then underwent transvaginal sonography for detection of intrauterine lesions, Status of endometrium and measurement of endometrial thickness as per procedure already mentioned. Hysteroscopy was performed in the operation theatre using $5 \mathrm{~mm}$ diagnostic sheath and 30 degree oblique view with $4 \mathrm{~mm}$ telescope (Karl Storz). The distending media used as normal saline. A pressure of 50-70 $\mathrm{mm}$ hg was required for adequate distension. Light source of $175 \mathrm{~W}$ with image recorder and camera also connected during the procedure.

After diagnostic hysteroscopy, targeted directed endometrial biopsies were taken if needed.

The sensitivity, specificity, PPV and NPV of these two diagnostic modalities were calculated using SPSS software.

\section{Result}

In the study, Table 1 and Fig 1 shows that $34.7 \%$ subjects belonged to $30-39$ years age group and mean age of intrauterine pathology is 35.5 years and shows maximum subjects belonged to upper middle class 
Table 1

\begin{tabular}{|l|c|c|}
\hline AGE GROUP & NUMBER (n) & PERCENT \\
\hline$<20$ & 5 & 6.6 \\
\hline $20-29$ & 17 & 22.7 \\
\hline $30-39$ & 26 & 34.7 \\
\hline $40-49$ & 20 & 26.7 \\
\hline$>50$ & 7 & 9.3 \\
\hline TOATAL(N) & $\mathbf{7 5}$ & $\mathbf{1 0 0}$ \\
\hline
\end{tabular}

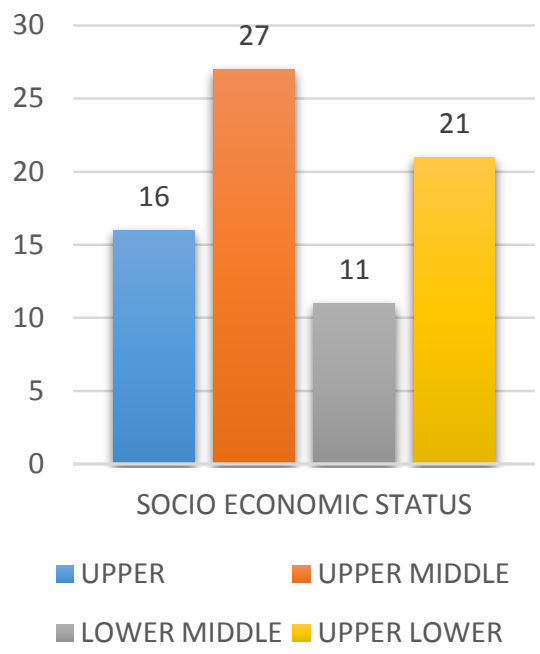

Fig 1

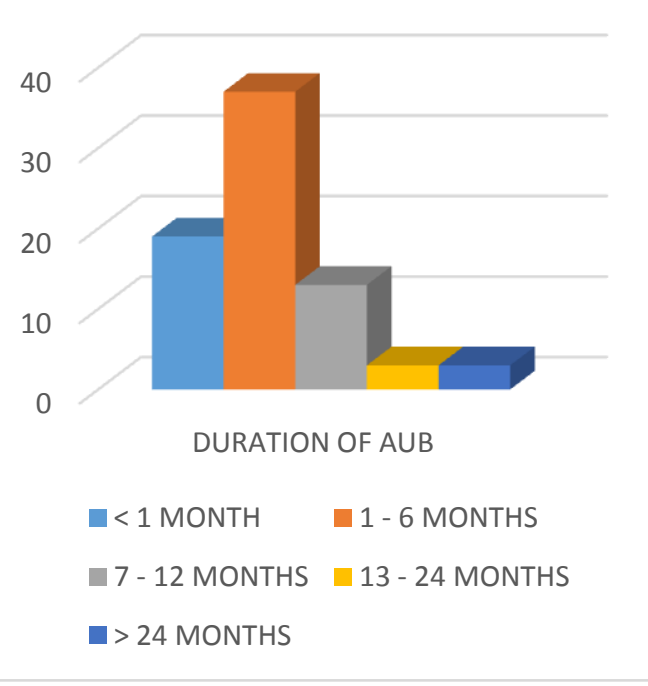

Fig 1

Figure 2, 3 showst hat $49.3 \%$ subjects complaining of abnormal uterine bleeding for last 1 to 6 months.

In my study, $58.7 \%$ subjects had heavy menstrual bleeding whereas inter menstrual bleeding and heavy prolonged bleeding found $8 \%$ and $10.7 \%$ cases respectively. $22.6 \%$ cases also have irregular menstrual bleeding (figure 4)

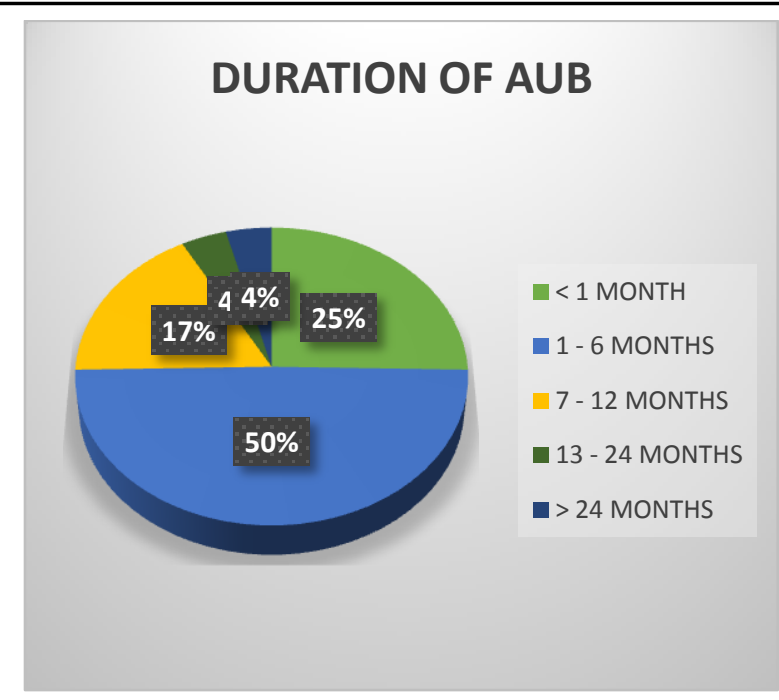

Fig 3

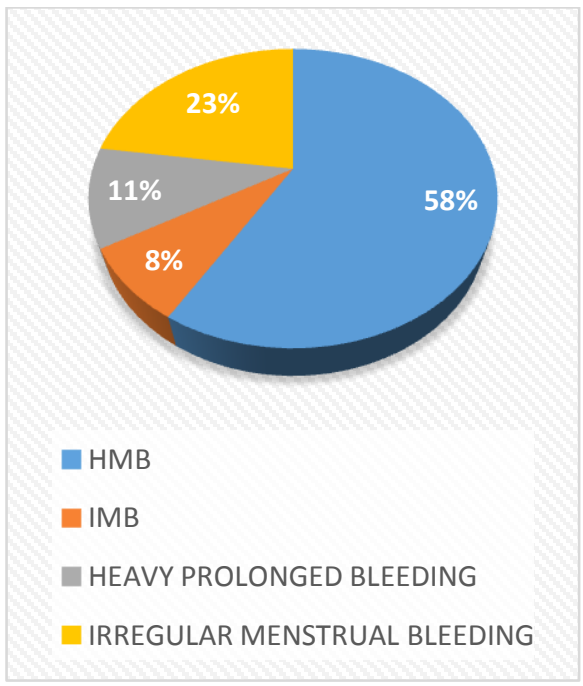

Fig 4

Table 2: Tvs findings

\begin{tabular}{|l|c|c|}
\hline PATHOLOGY & FREQUENCY (n) & PERCENTAGE \\
\hline Normal Endometrium & 6 & 8 \\
\hline $\begin{array}{l}\text { Proliferative } \\
\text { Endometrium }\end{array}$ & 11 & 14.7 \\
\hline Secretory Endometrium & 4 & 5.3 \\
\hline Endometrial Hyperplasia & 7 & 9.3 \\
\hline Endometrial Polyp & 24 & 32 \\
\hline Submucoasl Fibroid & 11 & 14.7 \\
\hline $\begin{array}{l}\text { Endometrial hyperplasia } \\
\text { +endometrial polyp }\end{array}$ & 6 & 8 \\
\hline Adenomyosis & 2 & 2.7 \\
\hline Missing IUCD & 2 & 2.7 \\
\hline Ca Endometrium & 2 & 2.7 \\
\hline TOTAL(N) & $\mathbf{7 5}$ & $\mathbf{1 0 0}$ \\
\hline
\end{tabular}

Table 2 shows TVS findings of the subjects, out of 75 cases 6 cases $(8 \%)$ were normal, 69 cases were abnormal pathology. Most common findings were endometrial polyp (32\%), followed by SMF (14.7\%), endometrial hyperplasia $(9.3 \%)$, both endometrial hyperplasia \& polyp (8\%), Adenomyosis $(2.7 \%)$, Ca Endometrium $(2.7 \%)$ respectively 
Table 3: Hysteroscopic findings

\begin{tabular}{|l|c|c|}
\hline $\begin{array}{l}\text { INTRAUTERINE } \\
\text { PATHOLOGY }\end{array}$ & FREQUENCY(n) & PERCENT \\
\hline Normal Cavity & 10 & 13.3 \\
\hline $\begin{array}{l}\text { Proliferative } \\
\text { endometrium }\end{array}$ & 1 & 1.3 \\
\hline $\begin{array}{l}\text { Endometrial } \\
\text { hyperplasia }\end{array}$ & 18 & 24 \\
\hline Endometrial polyp & 24 & 32 \\
\hline Submucosal fibroid & 12 & 16 \\
\hline Asherman syndrome & 3 & 4 \\
\hline Intra uterine Anomaly & 3 & 4 \\
\hline Ca endometrium & 2 & 2.7 \\
\hline Missing IUCD & 2 & 2.7 \\
\hline TOTAL(N) & $\mathbf{7 5}$ & $\mathbf{1 0 0}$ \\
\hline
\end{tabular}

Table 3 shows that 10 cases were normal, 65 cases were found abnormal with intrauterine pathology, among most common were endometrial polyp (32\%), followed by endometrial hyperplasia (24 $\%)$, SMF (16 \%) respectively. Intra uterine anomaly also found in 3 cases, missing IUCD found in 2 cases and carcinoma endometrium in 2 cases.

\section{Table 4}

\begin{tabular}{|l|c|c|c|c|c|c|c|c|}
\hline HPE REPORT & \multicolumn{3}{|c|}{ TVS } & \multicolumn{4}{c|}{ HYSTEROSCOPY } \\
\hline Endometrial hyperplasia & SNS & SPC & PPV & NPV & SNS & SPC & PPV & NPV \\
\hline Endometrial polyp & $36.3 \%$ & $80.5 \%$ & $33.3 \%$ & $88.8 \%$ & $\mathbf{6 3 . 6 \%}$ & $\mathbf{8 2 . 8 \%}$ & $\mathbf{3 8 . 4 \%}$ & $\mathbf{9 2 . 9 \%}$ \\
\hline SMF & $61.9 \%$ & $79.6 \%$ & $54.2 \%$ & $84.3 \%$ & $\mathbf{9 0 . 4 \%}$ & $\mathbf{9 0 . 7 \%}$ & $\mathbf{7 9 . 2 \%}$ & $\mathbf{9 6 . 0 2} \%$ \\
\hline Ca Endometrium & $45 \%$ & $92.7 \%$ & $69.2 \%$ & $82.2 \%$ & $\mathbf{8 4 . 6 \%}$ & $\mathbf{9 8 . 3 \%}$ & $\mathbf{9 1 . 6 \%}$ & $\mathbf{9 6 . 8 \%}$ \\
\hline
\end{tabular}

In my study, the sensitivity, specificity, PPV and NPV of hysteroscopy for endometrial hyperplasia were better than TVS $(63.6 \%, 82.8,38.4 \%, 92.9$ $\%$ vs $36.36 \%, 80.5 \%, 33.3 \%, 88.8 \%$ ). Again hysteroscopy was found to be more sensitive and specific in predicting endometrial polyp than TVS (90.4\%, $90.7 \%$ vs $61.9 \%, 79.6 \%$ ). After analysing it is also found that hysteroscopy is better than TVS in diagnosis of SMF as it is more sensitive and specific $(84.6 \%, 98.3 \%$ vs $45 \%$, $92.7 \%$ ). In diagnosis of $\mathrm{Ca}$ endometrium, it is established that both TVS and hysteroscopy has same sensitivity and specificity (100\%). Intrauterine anomaly is accurately diagnosed by hysteroscopy, where TVS failed to diagnose. Missing IUCD was better diagnosed by hysteroscopy as well as hysteroscopy directed removal of IUCD is an added advantage

\section{Discussion}

Abnormal uterine bleeding is a common gynaecological problem in OPD, but is often complex and difficult to diagnose its specific causes. While most patients have underlying benign diseases, thorough investigations are necessary, particularly in the perimenopausal woman for which AUB is the main reason women are referred to gynaecologists and accounts for two thirds of all hysterectomies . ${ }^{5}$

Careful history, physical examination and basic investigations including haematological, endocrinological, ultrasonography (TAS) are the most useful tools for starting the initial evaluation of AUB. Currently, the main diagnostic methods which are being used in the evaluation of AUB are transvaginal ultrasonography and diagnostic hysteroscopy. According to some studies, diagnostic hysteroscopy represents an indispensable presurgical investigation, although the value of transvaginal ultrasonography compared with hysteroscopy is yet not fully defined.

In this study, total number of AUB was $6 \%$ of which intrauterine pathology was found $7.5 \%$. As per national health portal, the AUB is reported to occur $9-14 \%$. Therefore, prevalence of AUB in our study is lower than national figure. ${ }^{6}$

In present study, after analysis of subjects according to bleeding pattern the most common bleeding pattern was heavy menstrual bleeding (58.7\%) which was not comparable to the study by Pillai SS et $\mathrm{al}^{7}$. They had $46.5 \%$ patients with menstrual complaints of menorrhagia.

Arnold $\mathbf{J}$ et $\mathbf{a l}^{8}$ also had Heavy menstrual bleeding (HMB) in maximum no. of cases 
(43.7\%). This may be due to pre-existing anaemia among the habitant of this north east state

In this study majority of subjects diagnosed to have endometrial polyp (32\%), endometrial hyperplasia (14\%) and submucosal fibroid (9\%) by TVS. A study by Arunabha et al found that endometrial hyperplasia (19 \%), submucosal fibroid $(6 \%)$, endometrial polyp $(16 \%)^{9}$

In present study the sensitivity, specificity, PPV, NPV for diagnosis of endometrial hyperplasia on TVS was $36 \%, 80 \%, 33 \%, 88 \%$ which does not correlated with findings of Shokouhi B et al ${ }^{10}$ .The sensitivity, specificity, PPV, and NPV were $88.25 \%, 90.7 \%, 84 \%, 97.7 \%$, and $84 \%$.

TVS showed a sensitivity and specificity of $45 \%$ \& $92 \%$ for submucosal fibroid, comparing to 77.3 $\%$ \& $76 \%$ found by a study done by Reddi et $\mathbf{a l}^{11}$. So, TVS is not very specific for submucosal fibroid as it can be mistaken for endometrial polyp.

In my study, endometrial hyperplasia found $24 \%$, endometrial polyp $32 \%$, and submucosal fibroid $16 \%$. Sheetal et al ${ }^{12}$ showed hyperplasia in $18 \%$, endometrial polyp $9 \%$, and sub mucosal myoma $11 \%$.

In present study the sensitivity, specificity, PPV and NPV for endometrial hyperplasia on hysteroscopy was $63.6 \%, 82.8 \%, 38.4 \%, 92.9 \%$ respectively.

\section{Conclusion}

Abnormal uterine bleeding is one of the most common gynaecological problem in reproductive and perimenopausal women. TVS is easily available, safe and acceptable in most secondary and tertiary care setting and is non-invasive. It should be continued as 1st line diagnostic tool in patients with AUB. Hysteroscopy is a better diagnostic method for intrauterine pathology in AUB. With combination of both TVS and hysteroscopy, the evaluation for AUB will be more accurate and will guide for appropriate management.

With growing incidence of abnormal uterine bleeding, it is imperative to further study the role of TVS and Hysteroscopy in evaluation of intrauterine pathology in abnormal uterine bleeding and validate their diagnostic accuracy.

\section{References}

1. Fraser IS, Hilary OD, Broder MS, Malcolm G. Munro MG. The FIGO Recommendations on Terminologies and Definitions for Normal and Abnormal Uterine Bleeding. Fertil Steril.2011; 5:385.

2. Bennett AR, Gray SH. What to do when she's bleeding through: the recognition, evaluation, and management of abnormal uterine bleeding in adolescents. Curr Opin Pediatr. 2014;26 (4):4139.

3. Bettochi S, Nappi L, Ceci O. Office hysteroscopy in obstetrics and gynecology clinics of North America: advances in laparoscopy and hysteroscopy techniques, Philadelphia: W.B. Saunders Company. 2004:6:41-54.

4. Alfhaily F, Ewies AA. The first line investigation of postmenopausal bleeding: transvaginal ultrasound scanning and endometrial biopsy may be enough. Int $\mathbf{J}$ Gynecol Cancer.2009;19:892-5.

5. O'Connor VM. Heavy menstrual loss. Is it really heavy loss? Med Today. 2003;4:519.

6. https://www.nhp.gov.in/disease/gynaecolo gy-and-obstetrics/abnormal-uterinebleeding

7. Pillai SS. Sonographic and histopathological correlation and evaluation of endometrium in perimenopausal women with abnormal uterine bleeding. Int $\mathbf{J}$ Reprod Contracept Obstet Gynecol. 2014;3(1):113-7.

8. Arnold JA, Saravanan S. A two year clinicopathological study of non-gravid women with abnormal uterine bleeding in a rural tertiary care centre in Tamilnadu: In Concurrence with The Figo Recommendations. JEMDS. 2015;4(63):10990-1000. 
9. Saha A, Goyal, BK, Gaur I, Sunil Sharma S. Transvaginal sonography versus hysteroscopy in evaluation of abnormal uterine bleeding. Medical journal armed forces india. 2015(71) $120-25$.

10. Shokouhi B. Role of transvaginal ultrasonography in diagnosing endometrial hyperplasia in pre-and post menopause women. Nigerian Med J: J Nigeria Med Assoc. 2015;56(5):353

11. Reddi R, Lakshmikantha G. Transvaginal sonography and saline infusion sonohysterography in the evaluation of abnormal uterine bleeding. J Obstet Gynecol India. 2010;60(6):511-5.

12. Acharya NS, Patil SG, Bhute SB, Inamdar SA, Shrivastava DS. Role of diagnostic hysteroscopy in abnormal uterine bleeding and its histopathologic correlation. J Gynecol Endos Surg. 2009;1(2): 